\title{
Ulrich Fastenrath
}

Lücken im Völkerrecht. Zu Rechtscharakter, Quellen, Systemzusammenhang, Methodenlehre und Funktionen des Völkerrechts

Schriften zum Völkerrecht, Bd. 93, Duncker \& Humblot, Berlin 1991, 339 S.

Die Habilitationsschrift von Fastenrath bietet mehr, als die Ủberschrift vermuten läßt. Der Autor behandelt nicht nur eingehend die Lückenproblematik im Völkerrecht, sondern bietet eine umfassende Methodenlehre des Völkerrechts, die auf (fast) alle Probleme dieses Rechtsbereichs eingeht. In diesem Rahmen arbeitet Fastenrath zunächst die verschiedenen rechtsphilosophischen Ansätze heraus, die in der Völkerrechtslehre der Mitgliedstaaten der Völkerrechtsgemeinschaft vertreten worden sind. Anschließend zeigt er auf, wie diese verschiedenen rechtsphilosophischen Ansätze zu einer unterschiedlichen Beantwortung der einzelnen Völkerrechtsprobleme führen. Dabei werden sowohl die Völkerrechtsverträge als auch die einseitigen Völkerrechtsakte, das Völkergewohnheitsrecht sowie die allgemeinen Rechtsgrundsätze und die verschiedenen Hilfsquellen des Völkerrechts eingehend behandelt.

Entscheidend ist dabei, daß Fastenrath aufgrund eingehender Analysen ein umfassendes System der Völkerrechtsordnung entwirft, das zu einer eindeutigen Bestimmung auch umstrittener Rechtsfragen führt. Hinzuweisen ist dabei darauf, da $\beta$ die allgemeine Methodenlehre mit dem Problem der Lückenfüllung im Völkerrecht eng zu einer systematischen Einheit verbunden werden. Es ist dabei beachtlich, in welchem Umfang Fastenrath nicht nur die völkerrechtliche, sondern gerade auch die rechtsphilosophische Literatur in seine Untersuchungen einbezogen hat.

Insgesamt gesehen, stellt die Arbeit einen erheblichen Fortschritt im Bereich der völkerrechtlichen Methodenlehre dar.

Albert Bleckmann

David I. Fisher

Prior Consent to International Direct Satellite Broadcasting

Utrecht Studies in Air and Space Law, Vol. 8, Martinus Nijhoff Publishers, Dordrecht / Boston / London 1990, 236 S.

Fishers Buch zum internationalen Satellitendirektfunk (DBS) erscheint in einer ambivalenten Phase der völkerrechtlichen Diskussion. Zwar zeigt der erst in jüngster Zeit stark ansteigende Absatz sogenannter Satellitenschüsseln, d.h. preiswerter kleiner Parabolantennen zum Satellitendirektempfang für private Nutzer, daß sich die seit den sechziger Jahren diskutierten Probleme des kommerziellen grenzüberschreitenden Satellitenfunks nun erst- 